\title{
Treatment guidelines for Hepatitis C in Spain
}

\author{
M Crespo-Casal
}

Servicio de Enfermedades Infecciosas.

Hospital Universitario Vall d'Hebron, Barcelona.

\begin{abstract}
The discovery of new orally administered drugs that can block different targets of the replication cycle of the hepatitis $\mathrm{C}$ virus (HCV) with major antiviral activity, has revolutionized treatment of this infection and relegated interferon-based treatments to a secondary position. The start up of the National Strategic Plan for Combating Hepatitis C, which acknowledges the greater efficacy and safety of oral antiviral drugs, as well as the agreements between the pharmaceutical companies and different government bodies has enabled the initial difficulties of access to these medicines due to their high cost to be overcome.

In this rapidly changing environment, the availability of a therapeutic guide based on a critical analysis of the available evidence, takes on special relevance and provides a basic support for medical practitioners involved in HCV treatment.

However, the speed with which new therapeutic options are included and the limited evidence in some clinical scenarios signifies a challenge for those responsible for scientific societies whose job it is to coordinate the preparation of therapeutic guides and to keep recommendations up to date.

In this review we analyze the treatment recommendations for HCV in a consensus document drawn up by the Spanish Association for the Study of Liver Diseases (AEEH), to contrast them with recommendations given by American and European associations that study hepatic diseases.
\end{abstract}

Key words: Hepatitis C; Antiviral Agents; Prisons; Administration, Oral; Antiviral Agents; Hepacivirus; Spain; Efficacy.

Text received on: 04/28/2015

\section{INTRODUCTION}

The aim of the guidelines is to produce therapeutic recommendations based on critical analysis of the published information that facilitate the clinical application of the available therapeutic alternatives. The speed with which orally administered drugs (OADs) for $\mathrm{HCV}$ infection have arisen, related administrative obstacles and heterogeneous access to these drugs have entailed a huge challenge for those responsible of updating treatment guidelines. This has also conditioned that recent updates included less effective or more toxic therapeutic regimens which were sometimes the only alternative available (for instance, GeSIDAGEHEP guidelines ${ }^{1}$, which are currently being reviewed). It is therefore desirable that the implementation of the National Strategic Plan for Combating Hepatitis C, which acknowledges the greater efficacy and safety of oral antiviral drugs, as well as the agreements between the pharmaceutical companies and
Text accepted on: 05/23/2015

different government entities, enables inequalities to be overcome and the standardization of therapeutic indications to be achieved.

In this review, we take the recently published consensus document ${ }^{2}$ drawn by the Spanish Association for the Study of Liver Diseases (AEEH) as a reference and we compare it with the recommendations issued by the European Association for the Study of the Liver (EASL) ${ }^{3}$ and the recommendations drawn up jointly by the American Association for the Study of Liver Diseases (AASLD) and the Infectious Diseases Society of America (IDSA) ${ }^{4}$. All of them include recommendations applicable to both HCV monoinfected patients and HCV-HIV coinfected patients.

\section{WHO SHOULD BE TREATED?}

Generally speaking, it is indicated to initiate therapy in all patients infected with $\mathrm{HCV}$. However, 
treatment priority should be given to patients with advanced fibrosis; clinical manifestations of the infection and as secondary prophylaxis (see Table1). This ranking of priority enables the rational administration of new drugs, which ultimately should aim the eradication of HCV.

\section{NEW ORAL HCV DRUGS}

Simeprevir is a protease inhibitor with a similar efficacy against genotype 1 to Telaprevir yet less toxic and active against genotype 4 too. Together with PegIFN and Ribavirin (PR) it is still recommended by the $\mathrm{AEEH}$ and the EASL for the treatment of genotypes 1 and 4 . However, in view of its toxicity and the availability of more effective combinations, its use should be exceptional or at least discouraged, as established by the AASLD/IDSA. Simeprevir together with Sofosbuvir has shown high efficacy against genotype 1 and is probably an effective combination against genotype 4 but we lack clinical information.

Sofosbuvir is a nucleotide analogue polymerase inhibitor with pan-genotypic activity and in comparison with the rest of oral HCV drugs it has a high genetic barrier therefore included in most of currently used regimens. Together with $\mathrm{PR}$ is a therapeutic alternative for genotype 1 and 4 patients. However, the availability of more effective combinations, especially for treatment-experienced patients and those with advanced fibrosis relegates sofosbuvir plus PR to exceptional use. The only clinical circumstance under which sofosbuvir together with PR can be considered as a preferential option is in cirrhotic genotype 2 and 3 patients.

Ledipasvir is an inhibitor of NS5a replication complex active against genotypes 1 and 4 , and to a lesser extent against genotype 3 . It only exists as a coformulation with Sofosbuvir, and therefore its use is influenced by the latter.
Daclatasvir is another NS5a inhibitor with pangenotypic activity. It can be used, together with Sofosbuvir, in patients infected by any genotype and it is a preferential option for genotype 3 non-cirrhotic patients.

Drugs manufactured by Abbvie $\AA$ are active against different viral targets: Paritaprevir/r (protease inhibitor co-dosed with Ritonavir); Ombitasvir (NS5a inhibitor) and Dasabuvir (non-nucleoside analogue polymerase inhibitor). They are indicated for genotype 1 patients (3D regimen: Paritaprevir/ r-Ombitasvir and Dasabuvir) or for genotype 4 patients (2D regimen: Paritaprevir/ $\mathrm{r}$ and Ombitasvir), in most of the cases (except for genotype $1 \mathrm{~b}$ non-cirrhotic patients) in combination with Ribavirin (RBV).

In oral $\mathrm{HCV}$ regimens the analysis of IL28B and of primary resistances is not recommended. Finally, we should consider the risk of potentially dangerous interactions of oral HCV drugs and antiretroviral or co-administered drugs (for instance, with amiodarone there is a risk of extreme bradycardia). Please consult www.hep-druginteractions.org for further information.

\section{RECOMMENDATIONS FOR GENOTYPE 1 PATIENTS}

\section{Sofosbuvir/Ledipasvir for untreated patients}

The trial ION-15 revealed that the rates of sustained virologic response (SVR) with this combination, with or without RBV, during 12 and 24 weeks, ranged between $97 \%$ and $100 \%$. A total of 2 patients out of the 134 included had virologic relapse. Thus the recommendation of including RBV to all cirrhotic untreated genotype 1 patients included in the AEEH guidelines (see Table 1) and in those by the EASL is not based on clinical data.

Table 1: Therapeutic indications for HCV with new oral drugs

\begin{tabular}{ll}
\hline & Advanced fibrosis (F3-F4) including decompensated cirrhosis \\
\cline { 2 - 2 } Priority treatment & $\begin{array}{l}\text { Pre or Post hepatic transplantation } \\
\text { Extra-hepatic relevant manifestations (for instance cryoglobulinemia, vasculitis, } \\
\text { intense fatigue, lymphoma) }\end{array}$ \\
\cline { 2 - 2 } & HBV or HIV co-infection or non-alcoholic steatosis \\
\cline { 2 - 2 } & High risk of transmission: IDUs, MSM, prisoners, pre-gestation \\
\hline Justified treatment & Moderate fibrosis F2 \\
\hline Not recommended & Fibrosis F0-F1 (treatment can be postponed) \\
\hline
\end{tabular}


The trial ION-3 ${ }^{6}$ compared an 8-week with and without $R B V$ regimen with a 12 week regimen without ribavirin for naive non-cirrhotic patients. The rate of SVR ranged between 93 and $95 \%$ and was similar for the three arms and hence the non-inferiority of the 8 week regimen was concluded. However, relapse rates were higher in the 8 week group (20/431) regardless of the use of RBV than in the 12 week group (3/216). Moreover, relapse rates were similar for patients with HCV ARN $\log 10<6.7 \mathrm{MIU} / \mathrm{mL}$ with $8(2 / 123)$ and $12(2 / 131)$ week regimens. Guidelines recommend the use of Sofosbuvir/Ledipasvir for 8 weeks in non cirrhotic patients with predictors of a favorable response (see Table 2). Nevertheless, extrapolating these results to clinical practice should be done with extreme caution.

\section{Sofosbuvir/Ledipasvir for previously treated patients}

In the ION-2 trial, rates of SVR with this combination for 12 or 24 weeks with or without RBV in genotype 1 previously treated patients ranged between $94 \%$ and $99 \%^{7}$. In cirrhotic patients the rates of SVR12 were higher with the 24 week regimens $(100 \%$ with or without ribavirin) when compared with the 12 week regimens $(86 \%$ without RBV and $82 \%$ with RBV). Grouped analysis of 513 cirrhotic naïve- and experienced-treatment patients included in phase 2 and 3 clinical trials, revealed that $96 \%$ of cirrhotic patients with previous therapeutic failure achieved SVR12 after 12 weeks of sofosbuvir/ ledipasvir plus ribavirin, and similar response rates were concluded for the 24 week regimen (with and without RBV) ${ }^{8}$.

The Sirius trial revealed that $96 \%$ of patients with compensated cirrhosis and previous therapeutic failure of $\mathrm{PR}+/-$ a protease inhibitor who underwent treatment with sofosbuvir/ledipasvir plus ribavirin for 12 weeks achieved SVR when compared with $97 \%$ of those who did so for 24 weeks ${ }^{9}$. These results suggest that for most of cirrhotic previously treated patients the regimen with sofosbuvir/ledipasvir plus ribavirin for 12 weeks can be enough (see Table 2). However, for patients who do not tolerate RBV or with advanced cirrhosis the optimal regimen should last 24 weeks, as recommended by the EASL and the AASLD/IDSA.

To conclude, sofosbuvir/ledipasvir plus ribavirin for 12 weeks achieved a rate of SVR $>95 \%$ in patients with a previous failure of sofosbuvir ${ }^{10}$.

\section{Paritaprevir/Ritonavir-Ombitasvir and Dasabuvir for naïve treatment patients}

In the SAPHIRE-I trial ${ }^{11}, 96 \%$ of previously untreated non cirrhotic patients treated with $3 \mathrm{D}$ plus RBV for 12 weeks achieved SVR: genotype 1a $95 \%$ and genotype $1 \mathrm{~b} 98 \%$. In another trial ${ }^{12}$, 12 weeks of the 3D combination with and without ribavirin were compared in naïve non-cirrhotic patients. For subtype 1B the rate of SVR12 was $99 \%$ for both regimen with and without ribavirin and for subtype 1a $90 \%$ for the regimen without RBV and $97 \%$ for the one including RBV. These results justify the use of the $3 \mathrm{D}$ regimen without ribavirin in naive non cirrhotic patients with subtype $1 \mathrm{~b} \mathrm{HCV}$ and the $3 \mathrm{D}$ regimen with RBV for subtype 1a patients (see Table 2). To conclude, the TURQUOISE-II trial ${ }^{13}$ compared the $3 \mathrm{D}$ combination plus ribavirin for 12 and 24 weeks in cirrhotic patients. $95 \%$ and $95 \%$ of previously untreated patients achieved SVR with no significant differences between both groups. The rates of SVR were $100 \%$ for genotype $1 \mathrm{~b}$ in both arms and $92-93 \%$ for genotype $1 \mathrm{a}$. These results justify the recommendation of the 3D plus RBV regimen for 12 weeks in cirrhotic previously untreated genotype $1 \mathrm{~b}$ or $1 \mathrm{a}$ patients (see Table 2). Yet the EASL and American guidelines recommend, as in the drugs' fact sheet, to treat all cirrhotic genotype 1a patients for 24 weeks.

\section{Paritaprevir/r-Ombitasvir and Dasabuvir in previously treated patients}

This combination plus ribavirin for 12 weeks achieved rates of SVR of $96 \%$ in the SAPPHIRE II trial ${ }^{14}$, in non cirrhotic previously treated with PR patients. The results were consistent for both genotype 1a patients $(96 \%)$ and patients with previous null response (95\%).

In previously treated genotype $1 \mathrm{~b}$ cirrhotic patients included in the TURQUOISE-II trial ${ }^{13}$, no significant differences were observed among between the 12 week and the 24 week regimens, regardless of previous response. However, in genotype 1a patients the rates of SVR were inferior in patients with previous null response who underwent the 12 week regimen $(40 / 50,80 \%)$ than in the 24 week group (39/42, $93 \%)$. SVR rates for patients with previous virologic relapse were $93 \%(14 / 15)$ and $100 \%(13 / 13)$ and in patients with previous partial response 100\% (11/11 and 10/10) after 12 and 24 weeks of treatment respectively.

Therefore, guidelines recommend the $3 \mathrm{D}$ regimen plus ribavirin for 12 weeks for previously treated 
Table 2: Therapeutic recommendations for genotype 1 patients

\section{PREVIOUSLY UNTREATED OR RELAPSE PATIENTS}

Sofosbuvir/Ledipasvir (400/90 mg once per day) +/- Ribavirin 100-1200mg/day

General recommendation: Sofosbuvir/Ledipasvir for 12 weeks

For cirrhotic patients: Sofosbuvir/Ledipasvir + Ribavirin for 12 weeks

For non cirrhotic patients with favorable response predictors: Sofosbuvir/Ledipasvir for 8 weeks

First-line options $\quad$ Paritaprevir/r Ombitasvir + Dasabuvir (3D) +/- Ribavirin 100-1200mg/day

a. Genotype 1b: 3D for 12 weeks (plus ribavirin in cirrhotic patients)

b. Genotype 1a: 3D+Ribavirin for 12 weeks

Sofosbuvir + Simeprevir +/- Ribavirin for 12 weeks

\begin{tabular}{ll}
\hline \multirow{2}{*}{ Second-line options } & Sofosbuvir + Daclatasvir $+/$ - Ribavirin for 12 weeks \\
\cline { 2 - 3 } & Sofosbuvir + Peg-interferon/Ribavirin for 12 weeks \\
\hline
\end{tabular}

Third-line options Simeprevir + Peg-interferon/Ribavirin for 24 weeks ${ }^{1}$

PREVIOUS THERAPEUTIC FAILURE PATIENTS

\begin{tabular}{ll}
\hline & $\begin{array}{l}\text { Sofosbuvir/Ledipasvir +/- Ribavirin } \\
\text { a. General recommendation: Sofosbuvir/Ledipasvir for 12 weeks. } \\
\text { b. Cirrhotic patients or previous failure of Sofosbuvir: Sofosbuvir/Ledipasvir + Ribavirin } \\
\text { for 12 weeks }\end{array}$ \\
\cline { 2 - 3 } First-line options & $\begin{array}{l}\text { Paritaprevir/r- Ombitasvir + Dasabuvir (3D) +/- Ribavirin 1000-1200 mg/day (there is no information } \\
\text { on this regimen for patients with previous failure of Boceprevir o Telaprevir }{ }^{2} \text { ) } \\
\text { a. Genotype 1b: 3D for 12 weeks (in cirrhotic patients plus Ribavirin) } \\
\text { b. Genotype 1a: 3D + Ribavirin for 12 weeks (in cirrhotic patients, for 24 weeks ) }\end{array}$ \\
\cline { 2 - 3 } & $\begin{array}{l}\text { Sofosbuvir + Simeprevir +/- Ribavirin for 12 weeks (poorly assessed in patients with previous failure } \\
\text { of Boceprevir or Telaprevir }{ }^{2} \text { ) }\end{array}$ \\
\hline Second-line options & Sofosbuvir + Daclatasvir +/-Ribavirin for 24 weeks \\
\hline Third-line options & $\begin{array}{l}\text { Sofosbuvir + Peg-interferon/Ribavirin for 12 weeks (recommendation based on real life cohorts, few } \\
\text { patients with failure of triple therapy with Boceprevir or Telaprevir) }\end{array}$ \\
\hline
\end{tabular}

Discontinuing therapy in patients with detectable HCV RNA levels in week 4 of treatment. The more recommendable regimens for previous failure of triple therapy with Boceprevir or Telaprevir are Sofosbuvir/Ledipasvir and Sofosbuvir/Daclatasvir

non-cirrhotic subtype $1 \mathrm{a}$ or $1 \mathrm{~b}$ patients. In cirrhotic previously treated subtype 1a patients, 24 weeks are recommended, regardless of previous response, although the grade of evidence for this recommendation for patients with previous relapse or partial response is poor ${ }^{13}$.

\section{Sofosbuvir and Simeprevir}

The COSMOS trial ${ }^{15}$ assessed this combination with and without ribavirin for 12 or 24 weeks. SVR12 rates were similar in naïve patients, 95\% (38/40), and previously treated patients, $91 \% / 116 / 127)$ and in the 12 week group, 94\% (77/82) and the 24 week group, $91 \%$ (77/85), regardless of ribavirin. Grouped analysis including the ribavirin-free groups revealed that $95 \%(20 / 21)$ of patients with FO-F3 fibrosis treated for 12 weeks and $86 \%(6 / 7)$ of cirrhotic patients achieved SVR12. All cirrhotic patients (10/10) treated for 24 weeks achieved SVR12. All relapses occu- rred among genotype 1a patients. We still do not know the role of ribavirin on the risk of relapse. In the HCV-TARGET 2.0 cohort $^{16}, 89 \%$ (269/303) of patients achieved SVR4 after 12 weeks of treatment with sofosbuvir and simeprevir +/- ribavirin: 92\% $(113 / 123)$ of non-cirrhotic patients; 87\% (156/180) of cirrhotic patients and $75 \%$ (61/81) of patients with decompensated cirrhosis. No significant differences were observed between patients treated with ribavirin $(87 \%)$ and without it $(86 \%)$. The rates of SVR4 were $95 \%(88 / 93)$ in subtype $1 \mathrm{~b}$ patients and $89 \%$ $(154 / 180)$ in subtype 1a patients. Multivariate analysis revealed that hypoalbuminemia, genotype $1 \mathrm{a}$, hepatic decompensated cirrhosis and previous failure of protease inhibitors were associated to a poorer response. In the TRIO cohort ${ }^{17}$, the rates of SVR12 with sofosbuvir and simeprevir, +/- ribavirin for 12 weeks were $88 \%(68 / 88)$ in naïve cirrhotic patients and $87 \%$ $(64 / 74)$ and $76 \%(53 / 70)$ in previously treated non cirrhotic and cirrhotic patients respectively. The rate 
of SVR12 was $82 \%$ in patients with previous therapeutic failure of protease inhibitors $(n=33)$ and $80 \%$ with previous failure of PR ( $n=75)$.

These results suggest that the probability of responding to sofosbuvir and simeprevir with or without ribavirin is lower in patients with genotype $1 \mathrm{a} \mathrm{HCV}$, hepatic cirrhosis and most probably in patients with previous failure of protease inhibitors.

In recently published trials, sofosbuvir and simeprevir for 12 weeks achieved a high rate of SVR12 in genotype 1 non-cirrhotic patients, both naïve (97\%) and experienced $(95 \%)^{18}$. In cirrhotic patients the rate of SVR with sofosbuvir + simeprevir for 12 weeks is lower in previously treated patients $(77 \%)$ than in naïve patients $(85 \%)$ and in subtype 1a patients with Q80K polymorphism (74\%) than in subtype 1a patients lacking this mutation $(92 \%)$ or in subtype $1 \mathrm{~b}$ patients $(84 \%)^{19}$. If jointly considered, these results can help us extrapolating recommendations by different guidelines to clinical practice: sofosbuvir and simeprevir +/- ribavirin for 12 weeks, regardless of the degree of fibrosis (AEEH, Table 2); sofosbuvir and simeprevir for 12 weeks in non-cirrhotic patients and plus ribavirin or for 24 weeks in all cirrhotic patients (EASL) or 24 weeks in all cirrhotic patients with or without ribavirin (AASLD/IDSA).

\section{Sofosbuvir and Daclatasvir}

Ninety-eight percent (164/167) of non-cirrhotic patients treated with this combination with or without RBV, achieved SVR12, including 84 of the 85 patients treated for 24 weeks: 44 naïve patients and 40 out of 41 patients with previous failure of $\mathrm{PR}$ and boceprevir or telaprevir. $98 \%(80 / 82)$ of naïve patients treated for 12 weeks achieved SVR12 20.

In the ALLY-2 trial 96\% (80/83) of naïve patients and $98 \%(43 / 44)$ of previously treated patients (15 of whom presented hepatic cirrhosis) achieved SVR after 12 weeks of treatment with sofosbuvir and daclatasvir without ribavirin ${ }^{21}$.

In the ALLY-1 trial ${ }^{22}, 82 \%(37 / 45)$ of patients (60\% of whom had been previously treated) with decompensated cirrhosis treated with sofosbuvir, daclatasvir and ribavirin (initial dose of $600 \mathrm{mg}$ per day) for 12 weeks achieved SVR12.

In the AEEH document sofosbuvir and daclatasvir with or without ribavirin are recommended as second therapeutic alternatives for 12 weeks in naive patients and for 24 weeks in previously treated patients (Table 2). The EASL recommends sofosbuvir and daclatasvir without ribavirin for 12 weeks in noncirrhotic patients and plus ribavirin or for 24 weeks in cirrhotic patients. Daclatasvir has not been approved by the FDA and is therefore not included in the American guidelines.

\section{Sofosbuvir and PR}

In the NEUTRINO trial ${ }^{23}, 89 \%$ of naïve patients treated with this regimen for 12 weeks achieved SVR: $92 \%(207 / 225)$ of subtype 1a patients; $82 \%(54 / 66)$ of subtype $1 \mathrm{~b}$ patients; $80 \%$ of cirrhotic patients and $92 \%$ of non-cirrhotic patients. In the TRIO cohort, the rate of SVR12 in naïve patients was $77 \%$. In previous failure patients: $77 \%$ (30/39) in non-cirrhotic patients and $62 \%(53 / 85)$ in cirrhotic patients. In patients with virologic relapse after PR treatment, sofosbuvir together with PR achieved a rate of SVR12 of $80 \%{ }^{24}$.

In another trial, sofosbuvir + PR were inferior to simeprevir + sofosbuvir in genotype 1a patients with compensated cirrhosis, both in naïve and previously treated patients with null response ${ }^{25}$.

In the document by the AEEH this regimen is considered a second option therapeutic alternative in previously untreated genotype 1 patients (Table 2). The EASL considers it a suitable alternative for both naïve and previously treated patients and its use is not recommended by the AASLD/IDSA.

\section{Simeprevir and PR}

The rates of SVR in naïve patients according to the registered trials were $80 \%(210 / 264)^{26}$ and $81 \%$ $(209 / 257)^{27}: 85 \%$ (228/267) for subtype 1 b; $84 \%$ and $58 \%$ in subtype 1a patients without and with Q80K polymorphism respectively; 84\% (317/378) in FO-F2 fibrosis patients; $73 \%(60 / 82)$ in $\mathrm{F} 3$ patients and $60 \%$ in $\mathrm{F} 4$ patients.

In previously treated patients the rate of SVR with simeprevir and PR was: $70 \%(163 / 234)$ in patients with previous partial response and $44 \%(63 / 145)$ in patients with previous null response ${ }^{28}$.

This regimen is considered as a third-choice alternative in the AEEH recommendations (Table 2) and is considered a valid alternative for both naïve and experienced patients according to the EASL. Its use is not recommended by the AASLD/IDSA.

\section{RECOMMENDATIONS FOR GENOTYPE 2 PATIENTS}

\section{Sofosbuvir and Ribavirin}

Between $86 \%$ and $97 \%$ of patients treated with sofosbuvir and ribavirin for 12 weeks achieved 
SVR $^{23}, 29-30$. The Photon 2 trial revealed that $89 \%$ $(17 / 19)$ of HIV co-infected genotype 2 naïve patients treated with that combination achieved SVR ${ }^{31}$. In the FUSION trial, previously treated patients achieved rates of SVR of $60 \%(6 / 10)$ in cirrhotic patients treated for 12 weeks and of $78 \%$ (7/9) in those treated for 16 weeks $^{29}$.

In the BOSON trial, the rate of SVR12 in genotype 2 previously treated cirrhotic patients treated with sofosbuvir and ribavirin for 16 and 24 weeks were $87 \%(13 / 15)$ and $100 \%(17 / 17)$ respectively ${ }^{32}$.

This is considered a first-line alternative by the AEEH (Table 3) with the recommendation of a 16 week regimen in cirrhotic previously untreated patients and a 16 to 24 week in previously treated patients, as recommended by other guidelines.

\section{Sofosbuvir + PR for 12 weeks}

The rate of SVR achieved with this regimen in 23 patients with previous failure of IFN/RBV was $96 \%$, including 13 of 14 cirrhotic patients ${ }^{33}$. In the BOSON trial, $94 \%(15 / 16)$ of genotype 2 cirrhotic previously treated patients achieved SVR12 after a 12 week regimen of sofosbuvir and $\mathrm{PR}^{32}$. This is a preferential option for previously treated patients according to AEEH (Table 3) and EASL guidelines and an alternative according to the AASLD/IDSA.

\section{RECOMMENDATIONS FOR GENOTYPE 3 PATIENTS}

\section{Sofosbuvir and Ribavirin for 24 weeks}

In the VALENCE trial, 85\% (212/250) of patients achieved SVR with this regimen, similar to naïve non cirrhotic patients (95\%) and cirrhotic patients (92\%). In previously treated patients $87 \%(87 / 100)$ of noncirrhotic patents and $62 \%$ of cirrhotic patients did $\mathrm{so}^{30}$.

In the PHOTON 2 trial, 89\% (97/106) of HIV co-infected patients obtained SVR: $86 \%$ (49/57) of previously untreated patients and $78 \%(18 / 23)$ of previously treated patients ${ }^{31}$. The results of the BOSON trial $^{32}$ reveal lower rates of SVR12 in previously treated patients than in naïve patients $(80 \%$ vs. $88 \%)$ and in cirrhotic patients than in non-cirrhotic patients (79\% vs. 97\%). These results justify the recommendations displayed in Table 3.

\section{Sofosbuvir and Daclatasvir}

The combination of sofosbuvir and daclatasvir for 12 weeks obtained rates of SVR of $97 \%$ and $94 \%$ in non cirrhotic naïve and previously treated patients respectively. In cirrhotic patients the rate of SVR was $58 \%$ in naïve patients and $69 \%$ in previously treated patients $^{34}$. An observational study concluded that $70 \%$ of patients $(n=114)$ suffering from decompensated cirrhosis (Child-Pugh $\geq 7$ ) achieved SVR12 after a 12 week regimen of this combination plus ribavi$\operatorname{rin}^{35}$. The Spanish guidelines recommend the addition of ribavirin and/ or a 24 week regimen in cirrhotic patients (Table 3 ).

\section{Sofosbuvir/Ledipasvir and Ribavirin for 12 weeks}

$64 \%(16 / 25)$ of naïve patients treated with sofosbuvir/ledipasvir for 12 weeks ( $\mathrm{n}=3$ cirrhotic patients) achieved SVR in comparison with $100 \%$ (26/26) of those treated with sofosbuvir/ledipasvir plus ribavirin $(\mathrm{n}=5 \text { cirrhotic patients })^{36}$.

Tabla 3. Recomendaciones de tratamiento en pacientes con genotipo 2 y 3.

\begin{tabular}{|c|c|}
\hline Genotype 2 & \\
\hline $\begin{array}{l}\text { Untreated or previous relapse } \\
\text { patients }\end{array}$ & Sofosbuvir + Ribavirin for 12 weeks (16 weeks in cirrhotic patients) \\
\hline \multirow{2}{*}{ Options for previous therapeutic failure } & Sofosbuvir + Peg-interferon/Ribavirin for 12 weeks \\
\hline & Sofosbuvir + Ribavirin for 16-24 weeks \\
\hline \multicolumn{2}{|l|}{ Genotype 3} \\
\hline \multirow{4}{*}{ Previously untreated patients } & Sofosbuvir + Peg-interferon/Ribavirin for 12 weeks \\
\hline & Sofosbuvir + Ribavirin for 24 weeks \\
\hline & Sofosbuvir + Daclatasvir, 12 weeks (not recommended in cirrhotic patients) \\
\hline & Sofosbuvir/Ledipasvir + Ribavirin for 12 weeks \\
\hline \multirow{3}{*}{ Previously treated patients } & Sofosbuvir + Peg-interferon/Ribavirin for 12 weeks \\
\hline & $\begin{array}{l}\text { Sofosbuvir + Daclatasvir } 12 \text { weeks (in cirrhotic patients it is recommended to } \\
\text { extend treatment } 24 \text { weeks or to add Ribavirin) }\end{array}$ \\
\hline & Sofosbuvir/Ledipasvir + Ribavirin for 12 weeks \\
\hline
\end{tabular}


In previously treated patients the rate of SVR12 was $82 \%$ (41/50): $73 \%(16 / 22)$ in cirrhotic patients and $89 \%(25 / 28)$ in non-cirrhotic patients ${ }^{37}$. According to these results, with a poor degree of evidence this combination is considered a therapeutic alternative in genotype 3 patients in the AEEH guidelines (Table 3) but is not recommended by either European or American guidelines.

\section{Sofosbuvir and PR for 12 weeks}

In the LONESTAR-2 trial ${ }^{33}, 83 \%$ (20/24) of previously treated patients achieved SVR with this combination, including 10/12 cirrhotic patients. In another trial which included 22 patients with previous failure of sofosbuvir and ribavirin, 91\% achieved SVR ${ }^{38}$.

In the BOSON trial ${ }^{32}, 93 \%(168 / 181)$ of genotype 3 patients achieved SVR12 after a 12 week treatment of sofosbuvir and PR. The rate of SVR12 was $86 \%$ $(30 / 35)$ in previously treated cirrhotic patients, therefore justifying the preferential use of this regimen in these patients (see Table 3).

\section{RECOMMENDATIONS FOR GENOTYPE 4 PATIENTS}

\section{Sofosbuvir and Ribavirin for 24 weeks}

In Egyptian patients ${ }^{39}$, the efficacy of sofosbuvir and ribavirin in a 24 week regimen was superior than the 12 week regimen both in naive patients $(100 \%$, $14 / 14$ vs. $79 \% 11 / 14$ ) and in previously treated patients ( $93 \% 14 / 15$ vs. $59 \% 10 / 17$ ). These results were confir- med by another trial with a comparable population ${ }^{40}$. In the PHOTON 2 trial, 84\% (26/31) of co-infected genotype4 naive patients achieved SVR: $83 \%(19 / 23)$ of non-cirrhotic patients and $88 \%$ (7/8) of cirrhotic patients. This is considered a preferential option by the AEEH guidelines and those by the AASLD/IDSA but not in the EASL recommendations.

\section{Paritaprevir/r - Ombitasvir + Ribavirin for 12 weeks}

This combination achieved a rate of SVR of $100 \%$ in genotype 4 non-cirrhotic patients both naïve $(\mathrm{n}=42)$ and previously treated $(\mathrm{n}=49)^{41}$. Although both the AEEH and the EASL recommend extending the regimen to 24 weeks for cirrhotic patients we lack clinical information supporting this recommendation (Table 4).

\section{Sofosbuvir/Ledipasvir for 12 weeks}

This combination has been assessed in 21 patients ( 9 of whom had cirrhosis) with a rate of SVR of $95 \%{ }^{42}$ and it is recommended as a first-line option, in spite of its poor degree of evidence, in all available guidelines (Table 4)

\section{Sofosbuvir and PR for 12 weeks}

The analysis of genotype 4 patients included in the NEUTRINO trial ${ }^{23}$ revealed a rate of SVR12 of $96 \%(27 / 28)$. We lack information regarding its efficacy in cirrhotic and previously treated patients.

Table 4: Therapeutic recommendations for genotype 4 patients

\begin{tabular}{|c|c|}
\hline & PREVIOUSLY UNTREATED OR RELAPSE PATIENTS \\
\hline \multirow{3}{*}{ First-line options } & Sofosbuvir/Ledipasvir for 12 weeks \\
\hline & Paritaprevir/r + Ombitasvir + Ribavirin for 12 weeks ( 24 weeks in cirrhotic patients). \\
\hline & Sofosbuvir + Ribavirin for 24 weeks. \\
\hline \multirow{3}{*}{ Second-line options } & Sofosbuvir + Simeprevir for 12 weeks (lack of results obtained in clinical practice) \\
\hline & Sofosbuvir + Peg-interferon/Ribavirin for 12 weeks \\
\hline & Sofosbuvir + Daclatasvir for 12 weeks ( 24 weeks in cirrhotic patients). \\
\hline \multirow{2}{*}{ Third-line options } & Simeprevir + Peg-interferon/Ribavirin for $24-48$ weeks \\
\hline & Daclatasvir + PR for 24 weeks \\
\hline & PREVIOUS THERAPEUTIC FAILURE PATIENTS \\
\hline \multirow{2}{*}{ First-line options } & Sofosbuvir/Ledipasvir for 12 weeks. \\
\hline & Paritaprevir/r + Ombitasvir + Ribavirin for 12 weeks in non-cirrhotic patients. \\
\hline \multirow{2}{*}{ Second-line options } & Sofosbuvir + Ribavirin for 24 weeks. \\
\hline & Sofosbuvir + Daclatasvir 12 weeks (24 weeks in cirrhotic patients). \\
\hline Third-line options & Sofosbuvir + Simeprevir for 12 weeks. \\
\hline
\end{tabular}




\section{Simeprevir + PR for 24-48 weeks}

This combination achieved rates of SVR of $83 \%$ (29/35) among naïve patients; $86 \%$ (19/22) in relapse patients, $60 \%(6 / 10)$ in partial responders and $40 \%$ $(16 / 40)$ in null responders. In cirrhotic naïve and relapse patients the rate of SVR was $72 \%(8 / 11)$ and in null responders $36 \%(5 / 14)^{43}$.

\section{Daclatasvir + PR}

Eighty-two percent $(67 / 82)$ of naivve patients who underwent this treatment for 24 to 48 weeks obtained SVR; $78 \%(7 / 9)$ of whom were cirrhotic patients. $67 \%(55 / 82)$ of patients obtained SVR after 24 weeks of treatment ${ }^{44}$.

PR based regimens with sofosbuvir, simeprevir and daclatasvir, specially the last two, are more complex and less effective than other available alternatives and although included in the AEEH and the EASL recommendations, its use should be exceptional.

\section{OTHER REGIMENS}

Last and in spite of the lack of clinical information on the efficacy of sofosbuvir together with simeprevir or daclatasvir in genotype 4 patients, guidelines extrapolate data obtained from genotype 1 patients and thus they are recommended as therapeutic alternatives.

To conclude, the approval of new oral HCV drugs has enabled the elaboration of highly effective regimens for most clinical scenarios. The degree of evidence for some of the recommendations however is limited and it justifies the differences observed among guidelines. The involvement of pharmaceutical companies, the administration and medical practitioners is of paramount importance for the implementation of a strategic plan which includes a rational use of new oral HCV drugs and which gives priority to patients at higher risk of progression, or in specific groups as a measure of secondary prophylaxis to achieve, in the medium term, the eradication of HCV infection.

Different scientific societies now face the challenge of updating treatment guideline to include the therapeutic innovations which are quickly arising. It would be desirable to sum up, that there was a reference document in Spain for all professionals involved in the treatment of Hepatitis C.

\section{ACKNOWLEDGEMENTS}

To Dr. Jordi Navarro for his critical review of this paper.

\section{CORRESPONDENCE}

Manuel Crespo Casal

Servicio de Enfermedades Infecciosas (Department of Infectious Diseases)

Hospital Universitario Vall d'Hebron, Barcelona.

email: mcrespo@vhebron.net

\section{BIBLIOGRAPHICAL REFERENCES}

1. Manejo de las hepatitis virales en pacientes infectados por el VIH. Guía de práctica clínica de Gesida (Management of viral hepatitis in HIVcoinfected patients. Gesida Clinical Practice guidelines) [Internet]. Madrid: Gesida; 2015 [cited 2015 Mar 27]. Available from: www.gesidaseimc. org/contenidos/guiasclinicas/2015/gesida-guiasclinicas-2015-Manejo_Hepatitis_Virales.pdf

2. Documento del II Consenso español sobre tratamiento de la hepatitis $\mathrm{C}$ (Consensus document on the treatment of Hepatitis C) [Internet]. Madrid: Asociación Española para el Estudio del Higado (Spanish Association for the Study of Liver Diseases); 2015 [cited 2015 Apr 23]. Available from: http://aeeh.es/wp-content/uploads/2015/04/IIConferenciade-consenso-sobre-el-tratamientode-la-hepatitis-C-de-la-AEEH.pdf

3. Clinical practical guidelines. EASL Recommendations on Treatment of Hepatitis C 2015. Journal of Hepatology [Internet]. 2015 [cited 2015 Apr 11]. Available from: http://www.easl.eu/medias/ cpg/HEPC-2015/Full-report.pdf

4. Recommendations for Testing, Managing, and Treating Hepatitis C [Internet]. Alexandria: AASLD; 2014 [cited 2015 Apr 12]. Available from: http://www.hcvguidelines.org/fullreport

5. Afdhal N, Zeuzem S, Kwo P, Chojkier M, Gitlin N, Puoti M, et al. Ledipasvir and Sofosbuvir for untreated HCV genotype 1 infection. N Engl J Med. 2014; 370(20): 1889-98.

6. Kowdley KV, Gordon SC, Reddy KR, Rossaro L, Bernstein DE, Lawitz E, et al. Ledipasvir and Sofosbuvir for 8 or 12 weeks for chronic HCV without cirrhosis. N Engl J Med. 2014; 370(20): 1879-88.

7. Afdhal N, Reddy KR, Nelson DR, Lawitz E, Gordon SC, Schiff E, et al. Ledipasvir and Sofosbuvir for previously treated HCV genotype 1 infection. N Engl J Med. 2014; 370(16): 1483-93.

8. Bourliere M, Sulkowski MS, Omata M, Zeuzem S, Feld JJ, Lawitz E, et al. An Integrated Safetyand Efficacy Analysis of $>500$ Patients with Compen- 
sated Cirrhosis Treated with Ledipasvir/ Sofosbuvir with or without Ribavirin, abstract 82. 65th Annual Meeting of the American Association for the Study of Liver diseases; 2014 November 7-11; Boston, USA.

9. Bourliere M, Bronowicki JP, de Ledinghen V, Hezode C, Zoulim F, Mathurin P, et al. Ledipasvir/ Sofosbuvir with or without ribavirin to treat patients with HCV genotype 1 infection and cirrhosis non-responsive to previous protease- inhibitor therapy: a randomised, double-blind, phase 2 trial (SIRIUS). Lancet Infect Dis 2015 Apr; 15(4): 397-404. DOI: 10.1016/ S1473-3099(15)70050-2.

10. Wyles D, Pockros P, Morelli G, Younes Z, Svarovskaia E, Yang JC, et al. Ledipasvir-sofosbuvir plus ribavirin for patients with genotype $1 \mathrm{HCV}$ previously treated in clinical trials of sofosbuvir regimens. Hepatology. 2015 Apr 2. DOI: 10.1002/ hep.27814. [Epub ahead of print].

11. Feld JJ, Kowdley KV, Coakley E, Sigal S, Nelson DR, Crawford D, et al. Treatment of HCV with ABT-450/r-Ombitasvir and Dasabuvir with ribavirin. N Engl J Med. 2014; 370 (17): 1594-603.

12. Ferenci P, Bernstein D, Lalezari J, Cohen D, Luo Y, Cooper C, et al. Y, PEARL-III Study; PEARLIV Study. ABT-450/r-Ombitasvir and Dasabuvir with or without ribavirin for HCV. N Engl J Med. 2014; 370 (21): 1983-92.

13. Poordad F, Hezode C, Trinh R, Kowdley KV, Zeuzem S, Agarwal K, et al. ABT-450/r-Ombitasvir and Dasabuvir with ribavirin for hepatitis $\mathrm{C}$ with cirrhosis. N Engl J Med 2014; 370: 1973-82.

14. Zeuzem S, Jacobson IM, Baykal T, Marinho RT, Poordad F, Bourliere M, et al. Retreatment of HCV with ABT-450/r-Ombitasvir and Dasabuvir with ribavirin. N Engl J Med. 2014; 370(17): 1604-14.

15. Lawitz E, Sulkowski MS, Ghalib R, RodriguezTorres M, Younossi ZM, Corregidor A, et al. Simeprevir plus Sofosbuvir, with or without ribavirin, to treat chronic infection with hepatitis C virus genotype 1 in non-responders to pegylated interferon and ribavirin and treatment-naive patients: the COSMOS randomised study. Lancet. 2014; 15; 384(9956): 1756-65.

16. Jensen DM, O’Leary J, Pockros P, Sherman K, Kwo P, Mailliard M, et al. Safety and efficacy of Sofosbuvir -containing regimens for hepatitis C: Real-World experience in a diverse, longitudinal observational cohort, abstract 45. 65th Annual Meeting of the American Association for the Study of Liver diseases; 2014 November 7-11; Boston, USA.
17. Douglas Dieterich, Bruce Bacon, Steven Flamm, Kris Kowdley, Scott Milligan, Naoky Tsai, et al Evaluation of Sofosbuvir and Simeprevir-based regimens in the TRIO network: academic and community treatment of a real-world, heterogeneous Population, abstract 46. 65th Annual Meeting of the American Association for the Study of Liver diseases; 2014 November 7-11; Boston, USA.

18. Kwo P, Gitlin N, Nahass R, Bernstein D, Rojter S, Schiff E, et al. A phase 3, randomised, openlabel study to evaluate the efficacy and safety of 12 and 8 weeks of simeprevir (SMV) plus sofosbuvir (SOF) in treatment-naive and-experienced patients with chronic HCV genotype 1 infection without cirrhosis: OPTIMIST-1, abstract LB14. Program and abstracts of the 50th Annual Meeting of the European Association for the Study of the Liver; 2015 April 22-26, Vienna, Austria.

19. Lawitz E, Matusow G, DeJesus E, Yoshida E, Felizarta F, Ghalib R, et al. A phase 3, open-label, single-arm study to evaluate the efficacy and safety of 12 weeks of simeprevir (SMV) plus sofosbuvir (SOF) in treatment-naive or -experienced patients with chronic HCV genotype 1 infection and cirrhosis: OPTIMIST-2, abstract LP04. Program and abstracts of the 50th Annual Meeting of the European Association for the Study of the Liver; 2015 April 22-26, Vienna, Austria.

20. Sulkowski MS, Gardiner DF, Rodriguez-Torres M, Reddy KR, Hassanein T, Jacobson I, et al. AI444040 Study Group. Daclatasvir plus Sofosbuvir for previously treated or untreated chronic HCV infection. N Engl J Med. 2014; 370(3): 211-21.

21. Wyles DL, Ruane P, Sulkowski M, Dieterich D, Luetkemeyer AF, Morgan TR, et al. Daclatasvir in Combination With Sofosbuvir for HIV/HCV Coinfection: ALLY-2 Study, abstract 151LB. CROI; 2015 Feb 23-26; Seattle, WA.

22. Poordad F, Schiff ER, Vierling JM, Landis C, Fontana RJ, Yang R, et al. Daclatasvir, Sofosbuvir, and Ribavirin Combination for HCV Patients with Advanced Cirrhosis or Post-transplant Recurrence: ALLY-1 Phase 3 Study, abstract LO8. Program and abstracts of the 50th Annual Meeting of the European Association for the Study of the Liver; 2015 April 22-26, Vienna, Austria.

23. Lawitz E, Mangia A, Wyles D, Rodriguez-Torres M, Hassanein T, Gordon SC, et al. Sofosbuvir for previously untreated chronic hepatitis $\mathrm{C}$ infection. N Engl J Med. 2013; 368(20): 1878-87.

24. Forns X, Lawitz E, Zeuzem S, Gane E, Bronowicki JP, Andreone P, et al. Simeprevir with peg 
interferon and ribavirin leads to high rates of SVR in patients with HCV genotype 1 who relapsed after previous therapy: a phase 3 trial. Gastroenterology. 2014; 146 (7): 1669-79.

25. Pearlman BL, Ehleben C, Perrys M. The combination of Simeprevir and Sofosbuvir is more effective than that of Peg interferon, Ribavirin, and Sofosbuvir for patients with hepatitis C-Related child's class A cirrhosis. Gastroenterology. 2015 Apr; 148(4): 762-70.e2.

26. Jacobson IM, Dore GJ, Foster GR, Fried MW, Radu M, Rafalsky VV, et al. Simeprevir with pegylated interferon alfa 2 a plus ribavirin in treatment- naive patients with chronic hepatitis $\mathrm{C}$ virus genotype 1 infection (QUEST-1): a phase 3 , randomised, double-blind, placebo-controlled trial. Lancet. 2014 2; 384(9941): 403-13.

27. Manns M, Marcellin P, Poordad F, de Araujo ES, Buti M, Horsmans Y, et al. Simeprevir with pegylated interferon alfa $2 \mathrm{a}$ or $2 \mathrm{~b}$ plus ribavirin in treatment-naive patients with chronic hepatitis C virus genotype 1 infection (QUEST-2): a randomised, double-blind, placebo-controlled phase 3 trial. Lancet 2014; 2; 384(9941): 414-26.

28. Reddy KR, Zeuzem S, Zoulim F, Weiland O, Horban A, Stanciu C, et al. Simeprevir versus telaprevir with peginterferon and ribavirin in previous null or partial responders with chronic hepatitis $\mathrm{C}$ virus genotype 1 infection (ATTAIN): a randomised, double-blind, noninferiority phase 3 trial. Lancet Infect Dis. 2015 Jan; 15(1): 27-35. 26.

29. Jacobson IM, Gordon SC, Kowdley KV, Yoshida EM, Rodriguez-Torres M, Sulkowski MS, et al. Sofosbuvir for hepatitis $\mathrm{C}$ genotype 2 or 3 in patients without treatment options. $\mathrm{N}$ Engl J Med. 2013; 368: 1867-77.

30. Zeuzem S, Dusheiko GM, Salupere R, Mangia A, Flisiak R, Hyland RH, et al. Sofosbuvir and ribavirin in HCV genotypes 2 and 3. N Engl J Med. 2014 May 22; 370(21): 1993-2001.

31. Molina JM, Orkin C, Iser DM, Zamora FX, Nelson M, Stephan C, et al, Sofosbuvir plus ribavirin for treatment of hepatitis $C$ virus in patients coinfected with HIV (PHOTON-2): a multicentre, open-label, non-randomised, phase 3 study. Lancet. 2015 Mar 21; 385(9973): 1098-106.

32. Foster GR. Sofosbuvir plus peg-IFN/RBV for 12 weeks vs. sofosbuvir/RBV for 16 or 24 weeks in genotype $3 \mathrm{HCV}$-infected patients and treatmentexperienced cirrhotic patients with genotype 2 HCV: the BOSON Study, abstract LO5. Program and abstracts of the 50th Annual Meeting of the
European Association for the Study of the Liver; 2015 April 22-26, Vienna, Austria.

33. Lawitz E, Poordad F, Brainard DW, Hyland RH, An D, Dvory-Sobol H, et al. Sofosbuvir with Peginterferon ribavirin for 12 weeks in previously treated patients with hepatitis C genotype 2 or 3 and cirrhosis. Hepatology. 2015 Mar; 61(3): 76975.

34. Nelson DR, Cooper JN, Lalezari JP, Lawitz E, Pockros PJ, Gitlin N, et al. All-Oral 12-Week Combination Treatment With Daclatasvir plus Sofosbuvir in Patients with hepatitis C virus genotype 3 infection: ALLY-3 Phase III Study. Hepatology 2015 Apr; 61(4): 1127-35.

35. Foster GR, McLauchlan J, Irving W, Cheung M, Hudson B, Verma S, et al. Treatment of decompensated HCV cirrhosis in patients with diverse genotypes: 12 weeks sofosbuvir and NS5A inhibitors with/without ribavirin is effective in $\mathrm{HCV}$ Genotypes 1 and 3, abstract O002. Program and abstracts of the 50th Annual Meeting of the European Association for the Study of the Liver; 2015 April 22-26, Vienna, Austria.

36. Gane EJ, Hyland RH, An D, Pang PS, Symonds WT, McHutchison JG, et al. Sofosbuvir/ledipasvir fixed dose combination is safe and effective in difficult to treat populations including geneotype-3 patients, decompensated genotype-1 patients and genotype-1 patients with prior sofosbuvir treatment experience, abstract 06. 49th EASL; 2014 April 9-13; London.

37. Gane E, Hyland R, An D, Svarovskaia E, Pang P, Symonds W, et al. High Efficacy of LDV/SOF Regimens for 12 Weeks for Patients With HCV Genotype 3 or 6 Infection. Abstract LB-11. $65^{\text {th }}$ Annual Meeting of the American Association for the Study of Liver diseases; 2014 November 7-11; Boston, USA.

38. Ruane PJ, Ain D, Riad J, Meshrekey RG, Stryker R, Wolfe PR, et al. Sofosbuvir Plus Ribavirin in the Treatment of Chronic HCV Genotype 4 Infection in Patients of Egyptian Ancestry. J Hepatol. 2015 May; 62(5):1040-6.

39. Esmat GE, Omar RF, Khairy M, Doss W, Shiha G, Hassany M, et al. Sofosbuvir plus Ribavirin in the Treatment of Egyptian Patients with Chronic Genotype $4 \mathrm{HCV}$ Infection, abstract $959.65^{\text {th }}$ Annual Meeting of the American Association for the Study of Liver diseases; 2014 November 7-11; Boston, USA.

40. Hezode C, Asselah T, Reddy KR, Hassanein $\mathrm{T}$, Berenguer M, Fleischer-Stepniewska K, et al. Ombitasvir plus paritaprevir plus ritonavir 
with or without ribavirin in treatment-naive and treatment-experienced patients with genotype 4 chronic hepatitis $\mathrm{C}$ virus infection (PEARL-I): a randomised, open-label trial. Lancet. $2015 \mathrm{Mar}$ 30. pii: S0140-6736(15)60159-3. DOI: 10.1016/ S0140-6736(15)60159-3.

41. Kapoor R, Kohli A, Sidharthan S, Sims Z, Petersen T, Osinusi A, et al. Treatment of Hepatitis C Genotype 4 with Ledipasvir and Sofosbuvir for 12 weeks: Results of the SYNERGY Trial. $65^{\text {th }}$ Annual Meeting of the American Association for the Study of Liver diseases; 2014 November 7-11; Boston, USA.
42. Moreno C, Hezode C, Marcellin P, Bourgeois S, Francque S, Samuel D, et al Efficacy and safety of simeprevir with PegIFN/ribavirin in naive or experienced patients infected with chronic $\mathrm{HCV}$ genotype 4. J Hepatol. 2015 May; 62(5):1047-55. doi: 10.1016/j.jhep.2014.12.031.

43. Hezode C, Alric L, Brown A, Hassanein T, Rizzetto M, Buti M, et al. Daclatasvir in Combination With Peginterferon Alfa-2a and Ribavirin for Treatment-Naive Patients With HCV Genotype 4 Infection: Phase 3 COMMAND-4 Results, poster 819. IDWeek; 2014 October 8-12, Philadelphia, EEUU. 